\title{
Rich nations are feeding research predators
}

\author{
Cite as: CMAJ 2017 October 23;189:E1322-3. doi: 10.1503/cmaj.109-5510
}

Posted on cmajnews.com on Oct. 3, 2017.

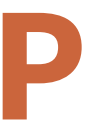

redatory journals are often dismissed as the research equivalents of stereotypical Nigerian scammers - products of poverty, opportunism and lax oversight in other countries. But researchers at the University of Ottawa warn that these publications have deeper roots in our own backyard than many people realize.

The number of predatory journals and articles has exploded with the rise of online open-access publishing. These journals exist to collect fees from authors, without much concern for the ethics, quality or dissemination of the research they publish. Yet their threat to scientific integrity in wealthy countries is often downplayed.

"If you asked anyone if it was a problem in Canada and the United States, the majority of folks would say it's not a big deal," says Dr. Manoj Lalu, an associate scientist and anesthesiologist at The Ottawa Hospital and assistant professor at the University of Ottawa. "They say not at our centre, not in our country."

But a closer look at who and what is being published tells a different story. Lalu coauthored a survey of nearly 2000 biomedical articles from more than 200 suspected predatory journals that found $57 \%$ of the corresponding authors came from upper-middle-income or high-income countries. The US ranked second only to India for overall number of articles. Canada ranked 12th, but was the third most common location of suspicious journals, after India and the US.

Some researchers who published in these journals were affiliated with top institutions, including Harvard University and the Mayo Clinic. The sample also included articles from almost every major Canadian university. "It wasn't just one or two," says Lalu.

Of the $17 \%$ of articles that reported a funding source, the US National Institutes

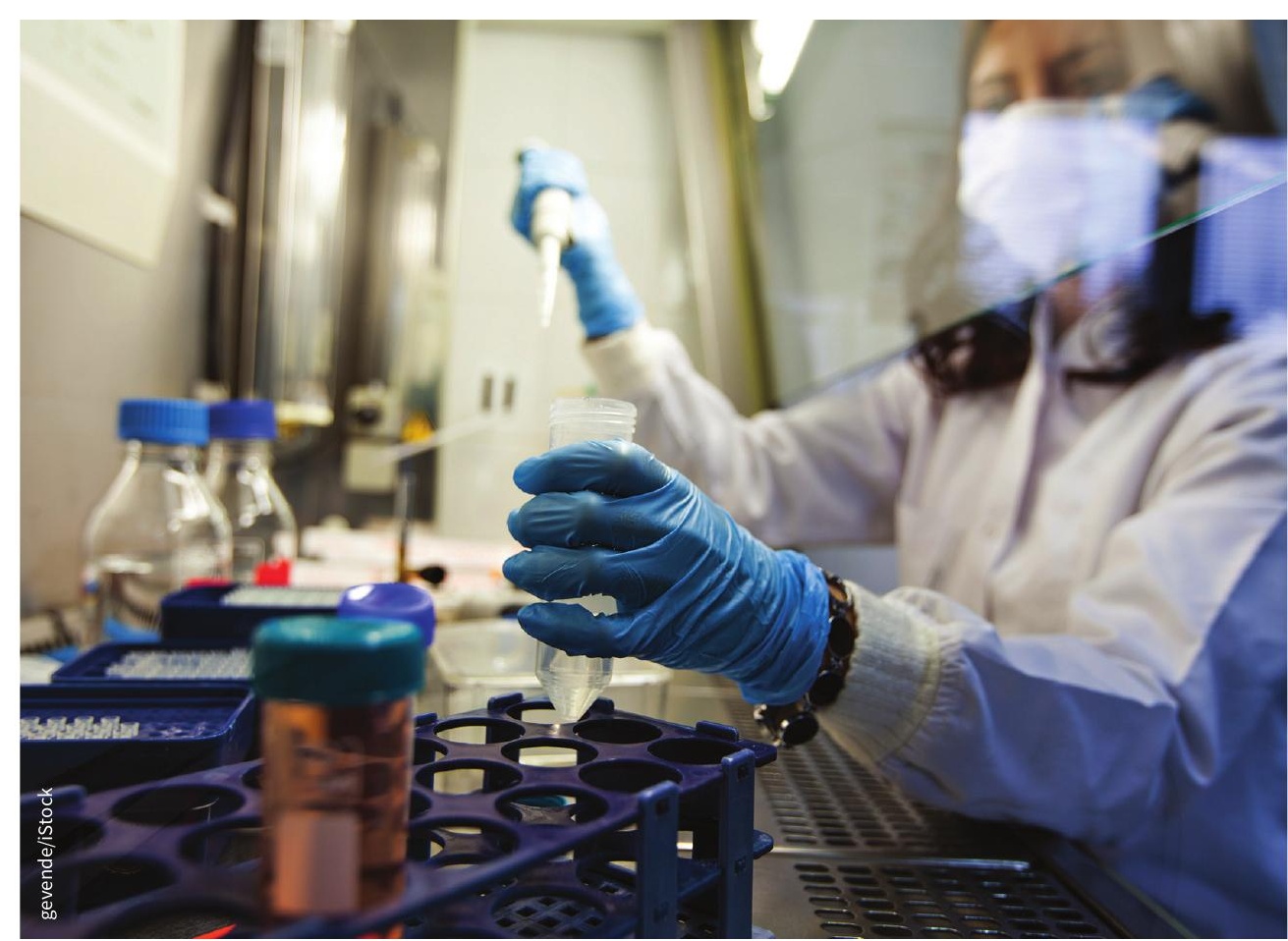

A Canadian study shows predatory journals include papers backed by top institutions and public funders.

of Health was the most frequently named. Canadian public funders were also named, including the Canadian Institutes of Health Research (CIHR) and the Social Sciences and Humanities Research Council (SSHRC).

"If we pulled another sample, we would almost certainly find other funders, and I suspect, almost every major funder in Canada," says Lalu.

He cautions that the paper's findings must be balanced against the fact that wealthy countries publish more research overall, and that some researchers and journals may lie about their locations and affiliations.

Even so, it points to a huge waste of tax dollars, as well as human and animal resources, says Lalu. "Over two million participants were involved in these stud- ies, and in terms of animal resources, over 8000 animals were being used."

These resources are going into research that "no one is going to read and no one is going to build on," he says. Most articles in predatory journals are never indexed and amount to little more than resumé padding for the authors. "They might show up in Google if you type exactly the right thing."

Without review by editors and peers, the quality of the articles can also be compromised. In the survey sample, Lalu says "completeness of reporting was far lower than what we would see in legitimate journals." Notably, only $40 \%$ of the studies that evaluated humans or animals mentioned approval by an ethics committee, compared to $90 \%$ of animal and $70 \%$ of human studies in mainstream journals. 
Lalu and his colleagues are urging researchers, institutions and funders to educate themselves and take action to curb predatory publishing in their midst. "It directly affects every single player in the whole ladder of research."

Lalu says most people aren't aware they're submitting to an illegitimate publication until it's too late. "These journals are quite tricky, and a lot of the names are very similar to legitimate journals."

Public funders are still coming to grips with the scope of predatory publishing in Canada, says Susan Zimmerman, executive director of Canada's Secretariat on Responsible Conduct of Research. "It has been growing, there's no doubt about that."

The secretariat manages allegations of breaches of policies at CIHR, SSHRC and the Natural Sciences and Engineering Research Council. Zimmerman says the current rules don't explicitly address predatory journals, and she isn't sure if the agencies vet the past publications of funding applicants.

"We do talk about rigor in research, and of course the agencies have general policies on open access," she says. A panel on responsible conduct of research will discuss "some more concrete measures" at its next meeting in October.

Part of the problem is that it's difficult to distinguish what makes a journal predatory, Zimmerman explains. There's also concern about penalizing researchers who were unwittingly duped. "Everyone wants a black-and-white way of doing this but I'm not sure it's necessarily that simple."

\section{Lauren Vogel, CMAJ}

Part one of a two-part series. Part two: Researchers may be part of the problem in predatory publishing 